\title{
Coulisses
}

Revue de théâtre

42| Printemps 2011

Racine : Théâtre et émotion

\section{Philippe Baron (1932-2009). Points de suspension}

\section{Lucile Garbagnati}

\section{CpenEdition}

Journals

Édition électronique

URL : https://journals.openedition.org/coulisses/724

DOI : $10.4000 /$ coulisses. 724

ISSN : 2546-9460

\section{Éditeur}

Presses universitaires de Franche-Comté

\section{Édition imprimée}

Date de publication : 15 février 2011

Pagination : 115-118

ISBN : 978-2-84867-316-5

ISSN : 1150-594X

\section{Référence électronique}

Lucile Garbagnati, «Philippe Baron (1932-2009). Points de suspension », Coulisses [En ligne], 42 | Printemps 2011, mis en ligne le 30 novembre 2016, consulté le 31 décembre 2022. URL : http:// journals.openedition.org/coulisses/724; DOI : https://doi.org/10.4000/coulisses.724 


\title{
Philippe Baron (1932-2009), Points de suspension ${ }^{1}$
}

\author{
LUCILE GARBAGNATI \\ M.C. retraitée de l'Université de Franche-Comté \\ et ancienne directrice de Coulisses
}

\begin{abstract}
«Madame Garbagnati, soyez heureuse. Nous venons de recruter un spécialiste du théâtre. Lorsque je l'ai reçu, j'ai cru voir la statue du Commandeur... » C'est en ces termes que M. le professeur Massonie, qu'on nommait encore, Doyen, de ce qu'on appelait alors la Faculté des Lettres m'a annoncé la venue d'un collègue, de rang professoral, chargé de prendre en charge les formations théâtrales.
\end{abstract}

À part la stature imposante, Philippe n’avait rien du Commandeur. Modeste, affable, conciliant, bienveillant, il cherchait avant tout à comprendre avant d'émettre un quelconque jugement. Sa présence a renforcé et développé l'existant: les modules de théâtre, le théâtre Universitaire, la revue Coulisses, et engagé la création d'une formation spécifique d'Études théâtrales. Les journées d'études, les colloques, les publications ont renforcé la présence de cette discipline au sein du Centre de recherches Jacques Petit.

\section{L'enseignement}

À l'époque, peu d'universités offraient des modules de théâtre et ceux qui existaient étaient dans la plupart des cas uniquement théoriques. L'originalité, à Besançon, est que la Faculté offrait des modules pour moitié théoriques et pour moitié pratiques à tous les étudiants de la faculté, tantôt comme obligatoires, tantôt comme optionnels. Philippe était assez réticent. Sa formation, agrégation de Lettres classiques, sa thèse d'état: Le Théâtre de mours en France de 1891 à

1. Mes remerciements à mesdames Andrée Baron et Jacqueline Razgonnikoff pour les compléments d'information. 
1914, sa fréquentation assidue de la Comédie française, le faisaient privilégier le texte, comme en témoigne son attention pour le travail du comédien dans L'Acteur en son métier². Cela ne l'empêcha pas de mettre sur pied le module "Écriture théâtrale » $^{3}$ où il se plut à regarder les créations scéniques des étudiants-auteurs-acteurs ou metteurs en scène. Plus tard, nous avons créé un module de licence qui, lui, ne portait que sur le répertoire. Les modules recevant de plus en plus d'étudiants, le DUMST attirant de plus en plus de candidats, la faculté voulant se doter d'une offre complète de formation aux métiers de l'art et de la médiation culturelle, il a été question de créer une filière théâtre autonome. Je me rappelle le nombre de réunions et de discussions sans fin sur le bien-fondé de cette nouvelle formation, sur son organisation, dans ces temps de diminution budgétaire et de chômage, où il écoutait les arguments et apaisait les passions ${ }^{4}$.

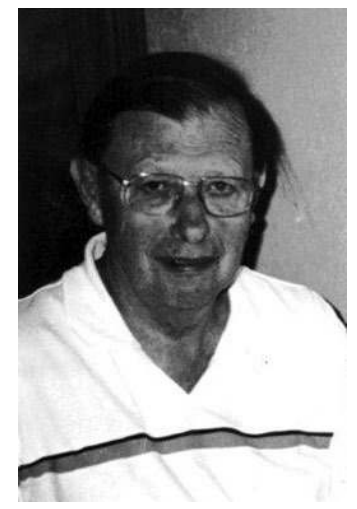

\section{La recherche}

Madame Jacqueline Razgonnikoff, bibliothécaire à la Bibliothèque de la Comédie Française, se souvient qu'il en était un lecteur assidu, s'intéressant surtout au théâtre naturaliste et aux auteurs allemands et nordiques. Elle le rencontrait également au séminaire de Jean-Claude Yon et à différents colloques sur le théâtre, malgré un état de santé précaire sur les derniers temps. De par sa thèse, il gardait une prédilection pour le théâtre de la fin du XIX ${ }^{\mathrm{e}}$ siècle et du début

2. L'acteur en son métier, textes réunis et présentés par Philippe Baron et Didier Souiller, Presses universitaires de Dijon, 2002.

3. Coulisses, $n^{\circ} 12$, mai 1995 , p. $87:$ «Le Module Écriture théâtrale ».

4. Sur l'évolution de l'enseignement du théâtre à la Faculté des Lettres, voir entre autres Coulisses, n²5, janvier 2002, p. 102 sq. 
du XX $X^{\mathrm{e}}$. Il fut un fidèle collaborateur des Cabiers Octave Mirbeau. Membre du Centre de recherches Jacques Petit, il développa les collaborations internationales et organisa plusieurs colloques dont Le Drame du XVI siècle à nos jours en partenariat avec le réseau CLUSE (Centre de liaison des universités de Suisse et de l'Est) ${ }^{5}$, une relation suivie avec l'université de Birmingham, matérialisée par deux colloques, le premier à Besançon en 1996, Aspects de la critique ${ }^{6}$, le second à Birmingham en 1998, Femmes et littérature 7 . Je me rappelle notre stupéfaction de découvrir non pas une ville sinistrée par la suppression de l'industrie mais une cité en pleine résurrection dont témoignait le Symphony hall, restauré dans son ancienne splendeur et modernisé pour accueillir toutes les formes de musique. Sa curiosité l'amena à développer avec la professeure Marie Miguet Ollagnier, une recherche interdisciplinaire de DEA sur deux ans, Littérature et médecines, sorte de préalable au projet de recherche "Théâtre et sciences »". Fidèle à la scène du XIXe et à sa curiosité, il publia le Théâtre libre d'Antoine et les théâtres de recherche étrangers ${ }^{10}$ en collaboration avec Philippe Marcerou, directeur de la Bibliothèque de la Sorbonne. Sa communication en 2002 au colloque Le Théâtre francais à l'étranger an XIX siècle ${ }^{11}$, Les représentations des pièces francaises au Volkstheater et au Burgtheater et de Vienne vers 1900, résume ses centres d'intérêt et sa recherche. Paradoxalement, sa modestie, comme celle d'ailleurs de sa collègue Anne Mantero, ne s'exhibe-t-elle pas dans le titre même de leur ouvrage collectif, Bagatelles pour l'éternité, l'art du bref en littérature ${ }^{12}$ ?

\section{Un théâtre pour tous}

Son goût pour le théâtre de répertoire n'avait rien d'élitiste et il a toujours soutenu le Théâtre universitaire de Franche-Comté, théâtre amateur au sein de

5. Le Drame du XVT siècle à nos jours, textes réunis par Philippe Baron, Éditions universitaires de Dijon, collection «Écritures », 2004.

6. Aspects de la critique, textes réunis par Philippe Baron et Ian Pickup, Annales littéraires de l'université de Franche-Comté, 1998, nº638.

7. Femmes et littérature, textes réunis par Philippe Baron, Dennis Wood, Wendy Perkins, Presses Universitaires Franc-comtoises, Annales littéraires de l'université de Franche-Comté, 2003, $\mathrm{n}^{\circ} 749$.

8. Littérature et médecine, textes réunis par Philippe Baron, Marie Miguet Ollagnier, Presses Universitaires Franc-comtoises, Annales littéraires de l'université de Franche-Comté, 2000, $\mathrm{n}^{\circ} 685$.

9. Programme qui s'est développé de 1998 à 2001 avec les colloques internationaux Théâtre et sciences, Quel répertoire théâtral traitant de la science?., Temps scientifique, temps théatral, Théatre et nouvelles technologies.

10. Théâtre libre d'Antoine et les théatres de recherche, Philippe Baron, Philippe Marcerou, L'Harmattan, 2007.

11. Le Théatre français à l'étranger au XIX'e siècle, sous la direction de $\mathrm{J}$. $\mathrm{Cl}$ Yon, Nouveau monde édition, collection « Histoire culturelle», 2008.

12. Presses Universitaires Franc-comtoises, Annales littéraires de l'université de Franche-Comté. 
l'université, dans toutes ses aventures. Il l'a plus particulièrement aidé lors de la mise en scène de L'Épidémie d'Octave Mirbeau, et reconnu son travail en l'invitant au colloque «Littérature et médecine ». Mais sa contribution majeure a été sa participation à Coulisses ${ }^{13}$, dont il a été membre du comité de lecture jusqu'à la fin. Il en a accompagné l'évolution. C'est lui qui a fortement contribué au changement de présentation, lorsque la revue est passée du format A4 au format A5, dans le numéro 20 de mai 1999. Il a également assumé le changement d'orientation de revue du Théâtre universitaire de Franche-Comté à celui de revue du théâtre de l'Université de Franche-Comté, publiant essentiellement des articles de recherche. Ses contributions sont diverses, et reflètent ses goûts et sa bienveillance. Qu'il rende compte d'ouvrages ${ }^{14}$ ou de colloques, qu'il soit critique de spectacle étudiant ou de metteurs en scène notoires, tout particulièrement ceux de la Comédie française par exemple : Léo Burckart de Gérard de Nerval et Alexandre Dumas ${ }^{15}$, La Cerisaie de Tchekhov ${ }^{16}$, La Forêt d'Alexandre Ostrovski17, il désire faire partager son expérience. Dans des articles plus approfondis, il partage sa connaissance de l'histoire du théâtre, Maison de Poupée d'Ibsen, fin et suite ${ }^{18}$, Le théâtre français en Allemagne ${ }^{19}$.

\section{Points de suspension}

Peter Brook conclut son ouvrage Points de suspension par l'apologue de Dieu qui envoie aux «gens de théâtre ne sachant plus quoi faire un message qui ne comporte qu'un seul mot "intérêt", suscitant beaucoup d'interrogations et de commentaires parmi les intéressés...»

"Avec ce mot, dit un autre à voix basse, nous pourrions aller loin, si loin. $»^{20}$ Et c'est ce qui peut résumer l'attitude de Philippe Baron.

13. Sur Coulisses, voir "De la pratique théâtrale à la nécessité de la mémoire», p. 129, Lucile Garbagnati in "Aspects de la critique », Coulisses, n 30 , "Coulisses a quinze ans ", p. 8 sq, Coulisses, n³1, «Éditorial», Frédérique Toudoire-Surlapierre, David Ball.

14. Coulisses, n¹1, janvier 1995, p. 57 : «Le Comédien désincarné de Louis Jouvet ».

15. Coulisses, n¹5, janvier 1997, p. 72.

16. Coulisses, $\mathrm{n}^{\circ} 20$, mai 1999, p. 158.

17. Coulisses, $\mathrm{n}^{\circ} 29$, janvier 2004, p. 133.

18. Coulisses, $\mathrm{n}^{\circ} 33$, janvier 2006, p. 275.

19. Coulisses, $\mathrm{n}^{\circ} 36$, octobre 2007, p. 29.

20. Points de suspension, p. 333 sq, Peter Brook, Éditions du Seuil, 1992. 